\title{
Encapsulamento e utilização de objetos de aprendizagem abertos SCORM para ensejar a avaliação formativa
}

Renato Luis de Souza Dutra

Orientador: Profa. Dra. Liane Margarida Rockenbach

Co-orientador: Profa. Dra. Liliana Maria Passerino

Data de defesa: 30 de julho de 2008

A avaliação formativa, apesar de ter sido inicialmente pensada por Scriven há mais de 30 anos, e ser discutida por diversos autores nas últimas décadas, ainda é pouco utilizada, tanto nos cursos presenciais como a distância. Somente nos últimos anos, com a adoção de ciclos de aprendizagem, a preocupação maior com o processo de ensino-aprendizagem e com o crescimento dos cursos a distância, essa abordagem de avaliação começou a ganhar mais importância. Na Educação a Distância (EAD), a avaliação formativa tem se mostrado uma excelente alternativa, por propiciar aos professores um acompanhamento mais próximo e mais individualizado de seus alunos e por permitir que professores e alunos regulem o processo de ensino-aprendizagem. Independente do processo avaliativo, o desenvolvimento de conteúdos digitais educacionais na forma de objetos de aprendizagem tem sido uma solução crescente na EAD. Para tanto, modelos de portabilidade e interoperabilidade, como o SCORM, proporcionaram uma grande evolução em termos de reusabilidade, portabilidade e interoperabilidade e, aliados à utilização de licenças que permitam a livre utilização, distribuição e modificação, possibilitam ao ambiente acadêmico facilmente intercambiar objetos de aprendizagem, independente de plataforma de hardware e software. Dessa forma, o desenvolvimento de objetos de aprendizagem, largamente utilizados na EAD, deveria levar em consideração o processo de avaliação formativa. Com base nessas constatações, a presente pesquisa buscou identificar quais critérios deveriam ser levados em consideração para o encapsulamento e a utilização de Objetos de Aprendizagem Abertos SCORM em Ambientes Virtuais de Aprendizagem, a fim de apoiar o processo de avaliação formativa.

Palavras-chave: Objetos de Aprendizagem. SCORM. Conteúdos Abertos. Avaliação Formativa. 